\title{
Effects of Soya Bean Oil and Vitamin C on Lipid Peroxidation and Antioxidant Biomarkers in Ethanol -Induced Oxidative Stress in Wistar Rats.
}

\author{
${ }^{1}$ Mallo, J. M., ${ }^{2}$ Mabrouk, M.A. ${ }^{1}$ Mshelia P.P and ${ }^{1}$ Tanko Y., \\ ${ }^{I}$ Department of Human Physiology, Ahmadu Bello University, Zaria, Nigeria \\ ${ }_{2}^{2}$ Department of Human Physiology, Bayero University, Kano, Nigeria
}

\begin{abstract}
The aim of this experiment is to investigate the effects of Soya bean oil and vitamin C on Ethanol induced oxidative stress in Wistar rats was evaluated. Oxidative stress was induced by oral administration of $20 \%$ ethanol $5 \mathrm{~mL} / \mathrm{kg} \mathrm{bw}$. The treatment lasted for 28 days, at the end of the treatment, the rats were fasted overnight and blood samples were collected directly from the heart via cardiac puncture into EDTA sample bottles and the plasma concentration of SOD, CAT, GPX and MDA was determined. The result revealed that Ethanol significantly $(p<0.05)$ increase the serum levels of SOD, CAT, GPX and MDA which are biomarkers of oxidative stress. However, treatment with soya bean oil and vitamin $C$ significantly $(p<0.05)$ decrease serum SOD, CAT, GPX and MDA levels. This study indicates the protective effect of vitamin $c$ and soya bean oil against ethanol-induced oxidative stress.
\end{abstract}

Key words: Ethanol, Oxidative Stress, Soya Bean Oil, Vitamin C, Lipid peroxidation, Antioxidants

\section{Introduction}

Alcohol is the widely used drug in the western society and it is one of the most popular drinks in Nigeria [1]. The relationship between alcohol consumption and health outcome is complex and multidimensional [2]. Alcohol accounts for about 1.8 million annual deaths globally and accounts for about $4 \%$ of the total disease burden [3]. Alcohol usage leads to dependence, which is a serious medical illness experienced by about $14 \%$ of alcohol users [4]. Alcohol causes about $\$ 184$ billion in expenditures arising from alcohol related chronic diseases such as heart diseases [5], Alzheimer's disease[6], liver diseases [7], diabetes mellitus [8]. These diseases contributes to the alcoholism related high morbidity and mortality. Chronic alcohol consumption induces oxidative stress due to increase generation of reactive oxygen species (ROS) and reduction in the activity of antioxidants. The reactive oxygen species generation induced by alcohol is believed to be specific to alcohol metabolism by cytochrome P450-2E (CYP2E1), which produces $\mathrm{H}_{2} \mathrm{O}_{2}$ in addition to acetaldehyde, while alcohol dehydrogenase (ADH) mediated produces only acetaldehyde [9]. Interaction of $\mathrm{H}_{2} \mathrm{O}_{2}$ with copper or iron produces reactive oxygen species during alcohol oxidation by alcohol inducible liver microsomal cytochrome P-450 enzymes [9]. The aim of this research is to determine the effect of Soya Bean Oil and Vitamin C on Lipid Peroxidation and Antioxidant Biomarkers on Ethanol -Induced Oxidative Stress.

\subsection{Location of Study}

\section{Materials and Methods}

This research was conducted in the Department of Human Physiology Faculty of Medicine, Ahmadu Bello University, Zaria. Nigeria and Department of Chemical Pathology, Ahmadu Bello University, Teaching Hopspital Shika,Zaria, Nigeria.

\subsection{Drugs}

All chemical and drugs were obtained commercially and were of analytical grade. Soya bean oil was purchased from Grand Cereal and oil mills Limited Jos, Nigeria.

\subsection{Animals Management}

Thirty five (35) Wistar rats of both sexes were used for this research; the animals were purchased from the animal house, Federal College of Animal Health, National Veterinary Research Institute, Vom, Plateau State, Nigeria. The rats were housed in the animal house of the Department of Human Physiology Faculty of Medicine, Ahmadu Bello University Zaria, Nigeria. The animals were kept in cages under normal environmental temperature and were fed with standard pellet diet and water given ad libitum. The rats were allowed to acclimatize to the laboratory environment for one week before the experiment commenced. This research was carried out in Ahmadu Bello University in accordance with the rules governing the use of laboratory animals as accepted internationally. 


\subsection{Induction of Oxidative stress}

Method described by [10] as modified by [11] in which oxidative stress was induced by oral administration of ethanol $(20 \% \mathrm{w} / \mathrm{v})$ at a dose of $5 \mathrm{ml} / \mathrm{kg}$, the treatment lasted for a period of four weeks was adopted in this study.

\subsection{Experimental design}

After the induction of oxidative stress in the Wistar rats, the animals were randomly divided into experimental and control groups. All the animals were sacrificed at the end of the four weeks. The rats were anaesthetized at the time of sacrifice by being placed in sealed cotton wool soaked chloroform inhalation jar. Blood was collected via cardiac puncture from each animal centrifuge and the serum was used for determination of the lipid peroxidation and antioxidant biomarkers. The Wistar rats were subdivided as follows;

Group $1(\mathrm{n}=7)$ : control Normal Wistar rats( Received Distilled water)

Group 2 (n=7): Received 20\% w/v Ethanol only

Group 3 (n=7): Received 20\% w/v Ethanol and $10 \mathrm{mg} / \mathrm{kg}$ of Vitamin C

Group $4(\mathrm{n}=7)$ : Received 20\% w/v Ethanol and $5 \mathrm{mg} / \mathrm{kg}$ of Soya Bean Oil

Group 5(n=7): Received 20\% w/v Ethanol, 10mg/kg Vitamin C and $5 \mathrm{mg} / \mathrm{kg}$ of Soya Bean Oil

\subsection{Determination of Lipid Peroxidation}

The level of thiobarbituric acid reactive substance, malondialdehyde (MDA) as an index of lipid peroxidation was evaluated on the plasma using the method of Draper and Hadley [12]. The principle of the method was based on spectrophotometric measurement of the colour developed during reaction of thiobarbituric acid (TBA) with MDA. The MDA concentration in each sample was calculated by the absorbance coefficient of MDA-TBA complex $1.56 \times 10^{5} \mathrm{~cm}^{-1} \mathrm{M}^{-1}$ and expressed as nmol mg ${ }^{-1}$ [13].

\subsection{Determination of Serum Catalase (Cat) Activity}

Catalase was analysed using NWLSST ${ }^{\mathrm{TM}}$ NWK-CAT01 Catalase activity assay kit (North West Life Science Specialties, LLC, Vancouver, WA 98662), as stated by the manufacturer. This is based on the method of [14] with modifications to increase robustness and convenience. Ultrospec Plus Spectrophotometer Model number 4054 at wavelength of $240 \mathrm{~nm}$ was used.

\subsection{Evaluation of Serum Superoxide Dismutase (SOD) Activity}

Superoxide dismutase activity was analysed using NWLSS ${ }^{\mathrm{TM}}$ NWK-SODO2 Superoxide dismutase activity assay kit ( NorthWest Life Science Specialties, Vancouver, WA 98662) as stated by the manufacturer. This is based on the method of [15] with modifications to increase robustness and reliability. Ultrospec plus Spectrophotometer Model number 4054 at wavelength of 540nm was used.

\subsection{Determination of Serum Glutathione Peroxidase (GPx)}

The enzymes belong to a family of selenoproteins whose function is to catalyze the reduction of various peroxides.Four types of GPx (GPx-1 to 4) has been identified in mammalian species. GPx-1 is the classic intracellular form while GPx-2, GPx-3 and GPx-4 are gastrointestinal, plasma and phospholipid hydroperoxidase forms respectively. The NWLSS ${ }^{\mathrm{TM}}$ Glutathione Peroxidase Assay kit was used which is an adaptation of the method of [16]. Glutathione Peroxidase catalyzes the reduction of hydrogen peroxide $\left(\mathrm{H}_{2} \mathrm{O}_{2}\right)$, oxidizing reduced glutathione (GSH) to form oxidized glutathione (GSSG). GSSG is then reduced by glutathione reductase (GSHR) and $\beta$-nicotinamide adenine dinucleotide phosphate (NADPH) forming NADP ${ }^{+}$ (resulting in decreased absorbance at $340 \mathrm{~nm}$ ) and recycling the GSH. Because GPx is limiting, the decrease in absorbance at $340 \mathrm{~nm}$ is directly proportional to the GPx concentration

The absorbance was read at $340 \mathrm{~nm}$ after 1,2 and 3 minutes against reagent blank using spectrophotometer (JENWAY, 6405). The absorbance for blank was subtracted from the sample reading to give the corrected value.Thus, $\mathrm{GP}_{\mathrm{X}}$ activity was calculated using 8.412 as the extinction coefficient:

$\mathrm{GP}_{\mathrm{X}}(\mathrm{U} / \mathrm{L})=8.412 \times \Delta \mathrm{A} 340 / \mathrm{min}$.

$$
\mathrm{U} / \mathrm{L}=\text { unit activity per liter }
$$

$\Delta$ A $340 /$ min $=$ Change in absorbance at $340 \mathrm{~nm}$ per minute [16]

\subsection{Data Analysis}

All the data are expressed as mean \pm SEM. Statistical comparisons were performed by one way analysis of variance (ANOVA) followed by Duncan's multiple range tests [ 17]. The results were considered statistically significant if the $\mathrm{p}$ values were 0.05 or less. 


\section{Results}

Table 1 Effects of soya bean oil and vitamin C on oxidative stress parameters in Wistar rats

\begin{tabular}{lcccc}
\hline Groups & $\begin{array}{c}\text { SOD } \\
(\text { Units/L) }\end{array}$ & $\begin{array}{c}\text { CAT } \\
(\text { Units/L) }\end{array}$ & $\begin{array}{c}\text { GPx } \\
(\text { Units/L) }\end{array}$ & $\begin{array}{c}\text { MDA } \\
(\mathrm{nmol} / \mathrm{L})\end{array}$ \\
\hline Normal control (NS) & $1.53 \pm 0.07$ & $42.00 \pm 0.91$ & $40.20 \pm 1.43$ & $1.33 \pm 0.05$ \\
Ethanol Induced & $2.13 \pm 0.09$ & $55.75 \pm 2.39$ & $53.60 \pm 1.44$ & $1.60 \pm 0.11$ \\
Ethanol + Vitamin C & $1.57 \pm 0.09^{\mathrm{a}}$ & $47.75 \pm 2.56^{\mathrm{a}}$ & $47.40 \pm 1.21^{\mathrm{a}}$ & $1.42 \pm$ \\
$0.11^{\mathrm{a}}$ & & & & \\
Ethanol + Soya oil & $1.47 \pm 0.13^{\mathrm{a}}$ & $49.00 \pm 0.82^{\mathrm{a}}$ & $45.40 \pm 3.44^{\mathrm{a}}$ & $1.40 \pm$ \\
$0.12^{\mathrm{a}}$ & & & \\
Ethanol + Vitamin C + Soya oil & $1.27 \pm 0.13^{\mathrm{a}}$ & $44.50 \pm 1.94^{\mathrm{a}}$ & $40.00 \pm 1.95^{\mathrm{a}}$ & $1.40 \pm$ \\
$0.13^{\mathrm{a}}$ & & & &
\end{tabular}

$\mathrm{a}=$ significance $(\mathrm{p}<0.05)$ when compared to Ethanol group not treated.

\section{Discussion}

SOD plays an important role in protecting the cells from oxidative damage by converting superoxide radicals into hydrogen peroxide, which is further metabolized by catalase to molecular oxygen and water [18 19, 20]. GPx is a major endogenous antioxidant, which counteracts free-radical-mediated damage [21], and a marker of oxidative stress. It forms an important substrate for other enzymes, which are involved in the freeradical scavenging [22]. SOD, CAT and GPx are induced in response to oxidative stress [18]. SOD is the first enzyme of the damage caused to cells by free radicals [22]. CAT and GPx are some of the several cellular antioxidant enzymes that provide a defense system for the scavenging of reactive oxygen metabolites [18]. The activity of superoxide dismutase (SOD) increased significantly $(\mathrm{p}<0.05)$ after 4 weeks of alcohol treatment as compared to the normal control group $(2.13 \pm 0.09$ and $1.53 \pm 0.07)$, but treatment with vitamin $\mathrm{C}$ produced significant $(\mathrm{p}<0.001)$ decreased in SOD activity as compared to the ethanol treated rats $(1.57 \pm 0.09$ as compared to $2.13 \pm 0.09)$, treatment with soya bean oil also produced significant $(\mathrm{p}<0.05)$ decreased in SOD activity as compared to the ethanol group $(1.47 \pm 0.09$, as compared to $2.13 \pm 0.09)$.However, the group that received both ethanol and soya bean oil also showed a significant $(\mathrm{p}<0.05)$ decreased in SOD $(1.27 \pm 0.13$ as compared to $2.18 \pm 0.09$ ). Also from table 1 , ethanol increased serum catalase level when compared to the normal control group while vitamin C significantly $(\mathrm{p}<0.05)$ decreased CAT activity when compared to the ethanol group $(47.75 \pm 2.56$ as compared to $55.75 \pm 2.39)$ also, as regard to the group that was treated with soya bean oil there was a significant $(\mathrm{p}<0.05)$ decrease in CAT activity as compared to the ethanol group $(49.00 \pm$ 0.82 as compared to $55.75 \pm 2.39$ ). The group that was treated with both vitamin $\mathrm{C}$ and soya bean oil showed a significant decrease in CAT when compared to the ethanol group (44.50 \pm 1.94 as compared to $55.75 \pm 2.39$ ). The GPx activity was significantly $(\mathrm{p}<0.05)$ increased following ethanol administration when compared to the normal rats $(53.60 \pm 1.43$ as compared to $40.20 \pm 1.43)$. The rats treated with vitamin $C$ showed a significant $(\mathrm{p}<0.05)$ decreased in serum GPx when compared to the ethanol-induced group $(47.40 \pm 1.21$ as compared to $53.60 \pm 1.44)$ also, the rats that received soya bean oil and both soya bean and vitamin $C$ showed a significant $(\mathrm{p}<0.05)$ decreased in GPx when compared to the ethanol group (45.40 \pm 3.44 as compared to $53.60 \pm 1.44)$ and $(40.00 \pm 1.95$ as compared to 1.95$)$. It can also be seen that alcohol also significantly $(\mathrm{p}<0.05)$ increased MDA concentration when compared to the normal rat $(1.33 \pm 0.11)$ However, the groups treated with vitamin $\mathrm{C}$ showed a significant $(\mathrm{p}<0.05)$ decreased in MDA as compared to the ethanol group $(1.42 \pm 0.11$ as compared to $1.60 \pm 0.11)$. Also, the rats treated with both vitamin $C$ and Soya bean oil produced a significant $(p<0.05)$ decreased in MDA as compared to ethanol group $(1.40 \pm 0.13$ as compared to $1.60 \pm 0.11)$. The increased in SOD, CAT and GPx activity in ethanol group in this study contradicted the report by[23] that their activities was decreased, but it agrees with the study by[11] which indicated that there was a significant increased in SOD and CAT activities following alcohol administration, which could be attributed to their increased synthesis due to induction [24]. Soya bean oil and vitamin C also decreased the elevated serum malondialdehyde concentration which is a biomarker of lipid peroxidation as an indication of oxidative stress. The increased in MDA level agrees with the finding of [25], which showed that there was an increased in MDA after ethanol administration. The decrease of MDA levels in ethanol + vitamin C and ethanol + soya bean oil treated rats may be partially due to a counteraction of the deleterious effects of lipid peroxidation by soya bean oil and vitamin $\mathrm{C}$ utilization, suggesting that soya bean oil and vitamin C plays an important role in repairing of lipid dysfunction led by alcohol-induced liver damage. The reduction observed in treatment with vitamin $\mathrm{C}$ and soya bean oil is an indication of the antioxidant potentials of vitamin $\mathrm{c}$ and soya bean oil. Flavonoids which are one of the components of soya bean have gained importance as scavengers of free radicals and a potent inhibitor of lipid peroxidation. 


\section{Conclusion}

Soya bean oil and Vitamin $\mathrm{C}$ has ameliorative effect in ethanol induced oxidative stress by decreasing the lipid peroxidation and antioxidant biomarkers in Wistar rats.

\section{References}

[1] J.A. Akpala, R.O. Bolaji, Adolescents and Psychosocial Problems. Lagos, Nigeria: Longman, 1991

[2] S. Das, V.K. Alagappan, D. Bagchi, H.S. Sharma, N. Maulik, D.K. Das, Coordinated induction of iNOS-VEGF-KDR-eNOS after resveratrol consumption: A potential mechanism for resveratrol preconditioning of the heart. Vascul. Pharmacol. 2005, 42, 281-289.

[3] D. Seth, P.J. Hogg, M.D. Gorrell, G.W. McCaughan, P.S. Haber, P.S. Direct effects of alcohol on hepatic fibrinolytic balance: Implications for alcoholic liver disease. Journal of Hepatology 2008, 48: 614-627.

[4] B.F.Grant, F.S.Stinson, T.C. Harford, Age at onset of alcohol use and DSM-IV alcohol abuse and dependence: A 12-year follow-up. Journal of Substance Abuse; 2001.13: 493-504.

[5] A. George, V.M. Figueredo, Alcohol and arrhythmias: A comprehensive review. Journal of Cardiovacular Medicine. (Hagerstown) 2010; $11: 221-228$

[6] V. Marinho, J. Laks, E. Engelhardt, D. Conn, Alcohol abuse in an elderly woman taking donepezil for Alzheimer disease. Journal of Clinical Psychopharmacology, 2006; 26: 683-685.

[7] A.I. Cederbaum, Y. Lu, D. Wu, Role of oxidative stress in alcohol-induced liver injury. Archives of Toxicology. 2009; 83: 519-548.

[8] D.O. Baliunas, B.J.Taylor, H. Irving, M. Roerecke, J. Patra, S. Mohapatra, J. Rehm, Alcohol as a risk factor for type 2 diabetes: A systematic review2009.

[9] J. Haoraha, S.H. Ramirez, N. Floreani, S. Gorantla, B. Morsey, Y. Persidsky, Mechanism of alcohol-induced oxidative stress and neuronal injury. Free Radic Biol Med 2008; 45(11): 1542-1550.

[10] D.M. Melissa, Y.A. Michael, J.K. Sandra, Vitamin E protects against alcohol-induced cell loss and oxidative stress in the neonatal rat hippocampus International Journal of Developmental Neuroscience 2004, 22: 363-377

[11] L.E. Ochuko, A.A. John, O.A. Rachael, O.Y. dejobi, S.O. Okafor, Adenekan, Protective effect of pineapple (Ananas cosmosus) peel extract onalcohol-induced oxidative stress in brain tissues of male albino rats. Asian Paicfic Journal of Tropical Disease, 2011;5-9

[12] T.Y. Faremi, S.M. Suru, M.A. Fafunso, U.E. Obioha, Hepatoprotective potentials of Phyllanthus amarus against ethanol-induced oxidative stress in rats. Food Chem Toxic 2008; 46(8): 2658-2664.

[13] H. Draper, M. Hadley, Malondialdehyde determination as index of lipid peroxidation. Methods in Enzymology 1990,186: $421-431$.

[14] H. Lowry, N.J. Rosebrough, A L. Farr, R.J. Randall, Protein measurements with the folin phenol reagent. Journal of Biological Chemistry 1951,193: 265-275.

[15] J.R.F. Beer, I.W. Sine, Spectrophotometric method for measuring the breakdown of hydrogen peroxide by catalase. Journal of Biological Chemistry 1952, 195: 133-140.

[16] Paglia, D.E, and Valentine, W.N. (1967): Studies on the quantitative and qualitative characterization of erythrocyte glutathione peroxidase. J. Lab. Clin. Med, 70:158-169.

[17] R.C.,Duncan., R.G., Knapp and M.C Miller,. (1977): Test of hypothesis in population Means. In: Introductory Biostatistics for the health sciences. John Wiley and Sons Inc. NY: 71-96.

[18] J.J.P. Martin, M. Dailey, E. Sugarman, Negative and Positive Assays of Superoxide Dismutase Based on Hematoxylin Autoxidation, Archives of Biochemistry and Physics 1987,255: 329-336.

[19] N.K. Garg, S.S.T. Mangal, A.V. Mehta, P. Suresh, R.K. Tyagi, Evaluation of anti-apoptotic activity of different dietary antioxidants in renal cell carcinoma against hydrogen peroxide. Asian Pacific Journal of Tropical Biomedicine 2011, 1(1): 57-63.

[20] I. Rahman, W. MacNee, Lung glutathione and oxidative stress: implications in cigarette smoking-induced airway disease. Amer. Jour. Physio. 1999; 277: 1067-1088.

[21] A.J. Thenmozhi, P. Subramanian, Antioxidant potential of Momordica charantia in ammonium chloride-induced hyperammonemic rats. Evid Based Complement Alternat Med 2010.

[22] S. Dewanjee, A. Maiti, R. Sahu, T.K. Dua, V. Mandal, Effective control of type 2 diabetes through antioxidant defense by edible fruits of diospyros peregrine. Evid Based Complement Alternat Med 2009.

[23] O.Y. Okafor, O.L. Erukainure, J.A. Ajiboye, R.O. Adejobi, F.O. Owolabi, S.B. Kosoko, Pineapple peel extract modulates lipid peroxidation, catalase activity and hepatic biomarker levels in blood plasma of alcohol-induced oxidative stressed rats. Asian Pac J Trop Biomed 2011; 1(1): 12-14.

[24] Corzo O, Bracho N, Vásquez A, Pereira A. Optimization of a thin layer drying process for coroba slices. J Food Engineer 2008; 8(3): 372-380.

[25] C. Daye, K. Hong, The Effect of LyciumBarbarumPolysaccharide on Alcohol-Induced Oxidative Stress in Rats. Molecules, 2011:16;2542-2550 